\title{
Análise fatorial confirmatória ou análise dos componentes principais? Uma comparação com dados de opinião pública do Brasil ${ }^{1}$
}

\author{
Confirmatory factor analysis or principal \\ component analysis? A comparison with public \\ opinion data from Brazil
}

\section{Gregório Unbehaun Leal da Silva*1}

Palavras-chave: Análise Fatorial; Eigenvalues; RMSR; Majoritarianismo.

Keywords: Factor Analysis;

Eigenvalues; RMSR; Majoritarianism.

\begin{abstract}
Resumo: O objetivo principal é contrapor duas técnicas de extração de fatores. A análise fatorial confirmatória é confrontada frente à análise dos componentes principais. Inspirado em um trabalho que comparara as técnicas (FABRIGAR et al., 1999), fez-se uso de bancos de dados de 2018/2019 para contrastar as duas técnicas na construção de fatores de opinião pública para o Brasil. As questões avaliadas referem-se a dimensão de apoio ao regime democrático e a economia, em ambos os métodos foram encontrados dois fatores. As diferenças encontradas, apontam para desempenho melhor do PCA quando se leva em consideração os autovalores, já o AFC sai-se melhor quando observado a controversa estatística RMSR. Conclui-se ressaltando a complementariedade das técnicas, bem como o fato de que o processo de extrair fatores, quando tem objetivos acadêmicos, não pode prescindir de teoria bem elaborada.
\end{abstract}

\begin{abstract}
The main objective is to contrast two factor extraction techniques. Confirmatory factor analysis is compared against principal component analysis. Inspired by a work that compared the techniques (FABRIGAR et al., 1999), databases from 2018/2019 were used to contrast the two techniques in the construction of public opinion factors for Brazil. The questions evaluated refer to the dimension of support for the democratic regime and the economy, in both methods two factors were found. The differences found point to a better performance of the PCA when taking into account the eigenvalues, whereas the AFC does better when the controversial RMSR statistic is observed. It
\end{abstract}

\footnotetext{
${ }^{1}$ Recebido em 01.09.2021; aceito em 27.11.2021.

*1 Doutorando do Programa de Pós-Graduação em Sociologia e Ciência Política da Universidade Federal de Santa Catarina. E-mail: gregoriosilva1986@gmail.com.
} 
concludes by emphasizing the complementarity of the techniques, as well as the fact that the process of extracting factors, when it has academic objectives, cannot do without a well-elaborated theory.

\section{Introdução}

A construção de fatores é uma técnica muito empregada nas ciências sociais (Matos e Rodrigues, 2019). Um exemplo de uso da técnica encontra-se no trabalho de Silva (2017). Nesse estudo, a técnica é empregada com intuito de verificar dados de opinião pública brasileiros. Da leitura desse trabalho ${ }^{2}$, do de Fabrigar et al., (1999) e do de Matos e Rodrigues (2019) surgiu a ideia de comparar dois tipos de técnicas de extração de fatores comumente utilizadas na construção de fatores: análise fatorial confirmatória (doravante, AFC) frente à da análise dos componentes principais (doravante, $\left.\mathrm{PCA}^{3}\right)$.

Fabrigar et al. (1999) aponta as vantagens da AFC frente à PCA no que concerne aos estudos de comportamento atinentes à psicometria, fazendo ressalvas, entretanto, à necessidade de interpelar com as expectativas teóricas prévias. Para empreender uma análise dessa dimensão, fazemos aqui uso de questões similares à de trabalhos (MORENO, 2019; BORNSCHIER, 2013; 2020) que analisaram a opinião pública de países da América Latina utilizando dessas técnicas. Em nosso trabalho, a análise se debruça sobre ondas mais recentes de três bancos de dados de amostragem nacional atinentes a um só país: o Brasil.

Utilizamos para esse trabalho seis questões do Latin American Public Opinion Project (doravante, Lapop) nos dados do atinentes ao Brasil na onda de $2018 / 2019^{4}$. Também fizemos uso de seis questões do banco de dados da World Values Survey ${ }^{5}$ (doravante, WVS) nos dados brasileiros da onda de 2018. Também foram utilizadas cinco questões do Estudo Eleitoral Brasileiro ${ }^{6}$ (doravante, ESEB) da onda de 2018.

Com esse trabalho, pode se verificar a comparação dos achados entre as duas técnicas para um contexto específico, um país que só recentemente parece ter encontrado algum nível de clivagem social (LAYTON et al., 2021), e alguma polarização, ainda que afetiva e assimétrica (FUKS; MARQUES; 2020; 2021). A comparação aqui proposta pode ser útil para pesquisadores interessados no estudo de contextos nacionais com alguma semelhança ao do Brasil de biênio 2018/2019.

\footnotetext{
${ }^{2}$ O trabalho de Silva (2017a) utiliza outra técnica em seu trabalho, a da Teoria da Resposta ao Item, que não será aqui detalhada

${ }^{3}$ Resultado da sigla em inglês para: Principal Component Analysis.

4 Disponível em: <https://www.vanderbilt.edu/lapop/Brazil_AmericasBarometer_201819_Technical_Report_W_101019.pdf> Acesso em 30 de julho de 2021

${ }_{5}^{5}$ Disponível em: <https://www.worldvaluessurvey.org > Acesso em 01 ago 2021.

${ }^{6}$ Disponível em: <https://www.cesop.unicamp.br/por/eseb> Acesso em 04 ago 2021.
} 
Para proceder tal análise comparativa entre AFC e PCA, o que se segue se dividirá em cinco partes. Na primeira, apresenta-se a comparação mais detida entre as técnicas de extração de fatores aqui estudadas. Na sequência, se procederá breve levantamento sobre o contexto estudado, a fim de que seja possível localizar melhor o cenário em que AFC e PCA serão testados, concomitantemente será apresentada as divisões e díades que serão fatoradas. $\mathrm{Na}$ terceira parte, são apontados os dados e algumas observações atinentes aos métodos ainda não contempladas na primeira parte. Na sequência, os resultados serão apontados. Por fim, apresenta-se a discussão e conclusão referentes aos achados.

\section{AFC e PCA: diferenças e semelhanças}

A análise fatorial é um método estatístico utilizado para descrever a variabilidade entre variáveis observadas e possivelmente correlacionadas em termos de um número potencialmente menor de variáveis não observadas chamadas fatores. AFC e PCA são dois diferentes tipos de extração de fatores dessa mesma técnica7. Segundo Silva (2017a) há um estreitamento das técnicas de análise fatorial oriundas da psicometria com a ciência política desde os anos 1950. A análise fatorial repousa " [...] na concepção de que os fenômenos psicológicos e sociais podem ter como causa comum fatores não considerados diretamente" (SILVA, 2017a, p.33).

A ideia fundamental do PCA é examinar a matriz de correlações de itens para reduzir as informações em um conjunto menor de componentes. Esses componentes podem formar a base para hipóteses sobre fatores latentes. $O$ PCA dentro dessa lógica poderia ser útil para formação de hipóteses sobre quais fatores empregar. É de se ressaltar, entretanto, que em pesquisas acadêmicas, a análise exploratória tem um papel complementar, uma vez que não se deve prescindir de uma forte ancoragem na literatura da área de estudo desejada.

Já a AFC parte do suposto de que já se tem expectativa prévia quanto ao relacionamento das variáveis. PCA e AFC são técnicas que diferem em seus objetivos finais. A AFC é uma técnica inferencial que testa hipóteses de validade de modelo de medida predefinido, pouco similar com o caráter exploratório do PCA. Essa questão torna interessante que incursões como as aqui propostas sejam seguidas por pesquisadores interessados em trabalhar com redução de

\footnotetext{
${ }^{7}$ Nem a análise fatorial exploratória (AFE), nem a teoria de resposta ao item (TRI) serão abordadas aqui. Recomenda-se a leitura de Matos e Rodrigues (2019) para maior entendimento da primeira. No que concerne ao TRI, recomendam-se os trabalhos de Silva (2017a) e de Laros (2005).
}

Caderno Eletrônico de Ciências Sociais, Vitória, v. 9, n. 1, pp. 112-138, 2021 
fatores. Em suma, a complementaridade das técnicas é o espírito desse curto estudo.

Figura 1: Matriz de correlação, ESEB 2018

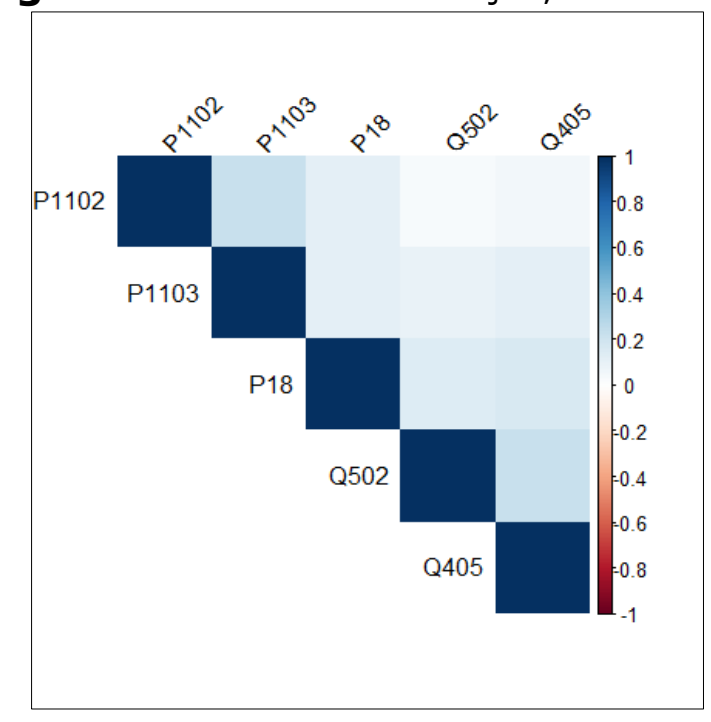

Fonte: elaborado pelo autor

Na PCA, o objetivo da extração de fatores é encontrar um conjunto de fatores que formem uma combinação linear das variáveis originais ou da matriz de correlações. Assim, se as variáveis $X 1, X 2, X 3, \ldots, X n$ são altamente correlacionadas entre si, elas serão combinadas para formar um fator, e assim, sucessivamente, com todas as demais variáveis da matriz de correlação. Em suma, a ideia fundamental do PCA é examinar a matriz de correlações de itens para reduzir as informações em um conjunto menor de componentes. Esses componentes podem formar a base para hipóteses sobre fatores latentes. Na presença de alta intercorrelação, os itens são áreas supostamente medindo o mesmo componente latente. Todos os itens devem ser carregados em todos os componentes.

Como observado na figura 1 , temos o exemplo da matriz de correlação dos dados do $\mathrm{ESEB}^{8}$, que foram utilizados na análise. A correlação encontrada entre 'P102' e 'P103' 'é à primeira vista, a maior encontrada. O que o PCA faz é a redução para que os mais correlacionados estejam juntos. Já a AFC parte de expectativa teórica prévia e conta com delimitação a priori do número de fatores e então os une da melhor maneira possível.

A redução de dados é especialmente possível pela aplicação da PCA e não pelo uso da AFC, havendo uma diferença fundamental entre os dois métodos: a PCA trabalha com a variância total observada, enquanto a AFC trabalha somente com a variância partilhada dos itens (variância erro e variância única são excluídas) (LAROS, 2005). Na AFC, os fatores são estimados para explicar

\footnotetext{
${ }^{8}$ As matrizes de WVS e Lapop constam no apêndice desse trabalho.
} 
as covariâncias entre as variáveis observadas, portanto os fatores são considerados como as causas das variáveis observadas.

Ainda sobre a PCA, deve-se apontar que os componentes são estimados para representar a variância das variáveis observadas de uma maneira tão econômica quanto possível. Os componentes principais são somas otimamente ponderadas das variáveis observadas, neste sentido, as variáveis observadas são consideradas as causas dos componentes principais (LAROS, 2005). Assim, recomenda-se a PCA, quando o objetivo é determinar o número mínimo de fatores que respondem pela máxima variância nos dados, sendo os fatores chamados componentes principais.

A AFC é usada para testar hipóteses, onde o pesquisador é guiado por teoria e testa em que medida as variáveis são representativas de um conceito/dimensão (Figueiredo; Silva, 2010). Dado essa premissa, por parte da AFC já partiremos com um número prévio de fatores esperados (como se verá na próxima seção), ao passo que na PCA essa se dará através de testes como o dos autovalores e screeplot.

Finch et al. (2017) indica que a técnica PCA é boa para lidar com variáveis sem distribuição normal, como as variáveis categóricas. Esse tipo de variável é comum em dados de opinião pública. No levantamento de Mendes e Ganga (2013), o PCA, mesmo predominantemente utilizada na análise de variáveis numéricas, é apontado como utilizado por "[...] inúmeros métodos de pesquisa em ciências sociais e gestão operacional utilizam variáveis qualitativas na proposição de construtos" (p. 84). A análise de componentes principais foi usada nesse trabalho como um design não linear ideal para dados nominais e ordinais (MEULMAN et al, 2004). A AFC, por ser uma técnica inferencial que testa hipóteses de validade de modelo de medida predefinido, não demandaria tamanha justificação. Entretanto, por se tratar de uma técnica de análise fatorial, também foi utilizada em outros trabalhos (FABRIGAR et al, 1999) com variáveis similares as que serão aqui testadas.

Com base em Fabrigar et al, 1999, Finch et al, (2017) e Laros (2005), tem-se por base a primeira hipótese: $H 1$ - Os resultados de AFC e PCA serão similares no que concerne ao número de fatores e questões localizados em cada fator.

Tendo como informação prévia o uso de PCA em estudos como os de Moreno [1999] (2019) e Dalton (2018), têm-se a segunda hipótese: H2 - 
Espera-se um melhor desempenho ${ }^{9}$ da PCA, dado seu uso em trabalhos de temática similar.

\section{Divisões na opinião pública na América Latina}

O caráter bidimensional da opinião dos cidadãos de países ricos encontrado no estudo de Dalton (2018) pode ser observado como uma tendência em estudos de comportamento político, dado o apontamento da pouca pertinência de adotar a perspectiva unidimensional clássica (por exemplo, direita-esquerda). Dois estudos recentes, um de caráter global (MALKA, LELKES e SOTO, 2019) e outro acerca do Brasil (SILVA, 2017a) mostram como a divisão histórica esquerda/direita não contempla tão bem a opinião pública como abordagens que adotem duas ou mais divisões.

Para marcar essa afirmação, convém citar que Malka, Lelkes e Soto (2019) analisando dados do WVS de 99 nações, concluíram que o "combo" que associa visão econômica privatista e posição conservadora nos costumes como direita e o oposto como esquerda não é comum na maior parte dos países. Muito pelo contrário, associações entre conservadorismo e visão mais próestado na economia são positivamente correlacionadas. Esse achado, denota a pertinência de se evitar tratar o universo da opinião dos cidadãos como meramente uma linha contínua da esquerda para direita. A proposta de construção de um panorama multidimensional parece mais adequada ${ }^{10}$, dada a complexidade do fenômeno político contemporâneo.

E na América Latina? A maior parte dos sistemas partidários da América Latina se constituiu (ou reconstituiu) nas últimas décadas, com distintas configurações no que diz respeito às experiências não democráticas, à manutenção ou inexistência de partidos anteriores no sistema e de sua relação com o eleitorado, ao papel dos cidadãos na política, etc.

Por exemplo, Colômbia, Costa Rica e Venezuela gozaram de décadas de competição política, ininterrupta até os anos 1980. Enquanto isso, na Argentina, no Chile e no Uruguai, o sistema partidário conformado no período pós-ditatorial conservou características de períodos anteriores, nos quais houve competição eleitoral. Já no Brasil, México, Paraguai e na maioria dos países da América Central, a transição para a democracia implicou na construção de novos partidos. Dada essa especificidade, é justo tentar compreender se achados como os de Dalton (2018) são, ao menos em parte, úteis para pensarmos outros contextos.

\footnotetext{
9 Os critérios são delimitados na seção "DADOS E MÉTODOS".

${ }_{10}$ Os achados de Malka, Lelkes e Soto (2019), ao apontar para multidimensionalidade, também são questionadores quanto à estudos que associam padrões de comportamento político de direita e esquerda à diferentes traços de personalidade.
}

Caderno Eletrônico de Ciências Sociais, Vitória, v. 9, n. 1, pp. 112-138, 2021 
Com base exclusivamente nos dados da demanda política (os cidadãos), Moreno (2019) identifica divisões na América Latina, Europa Oriental e Europa Ocidental que, às vezes, mas nem sempre, têm uma base estrutural. Análises discriminantes revelam quais dessas questões dividem a base dos alinhamentos partidários-cidadãos e, portanto, refletem-se no sistema partidário.

No que concerne ao caso brasileiro e da maior parte dos outros países latino-americanos analisados, o autor encontrou três divisões políticas principais compondo o contexto nacional. Quais sejam: 1- "Left-Right materialism", composta pela tradicional clivagem econômica. 2- "Liberal-Fundamentalist", composta por questões de cunho cultural, comuns a países com regime democrático recente, como aborto, nacionalismo e religiosidade. 3"Democratic-Authoritarian", que se refere às divisões entre partidários e oponentes do governo democrático, refletindo vencedores e perdedores da democratização.

É importante ressaltar que dois trabalhos de Bornschier $(2013 ; 2020)$ encontraram de 1 a 3 clivagens políticas na América Latina. Quando comparado com Moreno (1999), há uma variação muito maior entre os países, fato que parece ocorrer pela escolha de dados de anos posteriores aos de Moreno. Ainda em diálogo com estudos, como os de Moreno (2019), Deegan-Krause (2007) e Bornschier $(2013 ; 2020)$, é possível perguntar se há persistência de divisões ao longo do tempo, o que nos leva ao caso brasileiro e requer uma análise mais aprofundada.

Embora esse não seja o objetivo primordial do texto, é interessante fazer uso de dados recentes do país, afim de comparar as duas técnicas de extração, uma vez que essa dúvida pode ser a mesma de muitos pesquisadores que se debruçarem com a tentativa de reduzir dados a ponto de torná-los mais palpáveis.

A eleição de Jair Bolsonaro faz parte do contexto brasileiro mais recente. Esse, é relacionado com o crescente antipartidarismo (FUKS; RIBEIRO; BORBA, 2021) e sua consequente baixa aceitação ao direito dos adversários de competir. A inadequação de parte dos brasileiros quanto à requisitos considerados mínimos (DAHL, 2005; WELZEL, 2013; SILVA, 2021) para adesão ao jogo democrático liberal e sua relação com o voto ou partidarismo, entretanto, não é o foco. A proposta de análise dos dados aqui presente dialoga com a verificação das opiniões sobre issues que potencialmente dividem o público.

A verificação aqui proposta é uma comparação de dois diferentes eixos que comporão os fatores prévios da AFC: a divisão sobre o regime democrático

Caderno Eletrônico de Ciências Sociais, Vitória, v. 9, n. 1, pp. 112-138, 2021 
e a divisão sobre economia, sem, entretanto, buscar quaisquer conotações associadas à estudos eleitorais.

A divisão chamada aqui de 'democracia' será composta de elementos de aceitação do rival, e avaliação indireta do regime e concepção majoritária de democracia. Será possível que essa divisão presente nos anos 1990 (MORENO, 2019) esteja presente novamente? Seguindo achados recentes de Albertus e Grossman (2021), que incluem Brasil, esse parece ser o caso.

Os resultados aqui encontrados podem incidir mais luz sobre essa questão. Àqueles se opõem aos requisitos mínimos de democracia liberal (DAHL, 2006; WELZEL 2013; SILVA, 2021) são chamados de autoritários, seguindo Moreno (2019). Para essa avaliação são utilizados dados do Lapop. Uma avaliação indireta do regime também é utilizada, para esta dimensão foram utilizadas questões da WVS.

Outro conceito recém apresentado para aferir alguns que contestam preceitos mínimos de democracia liberal ${ }^{11}$ é 0 de majoritarianismo ${ }^{12}$ (GROSSMAN et al., 2021). Os dados do Eseb permitiram testar essa dimensão. "Majoritarians enable power grabs not in spite of their democratic ideals, but because of them. For majoritarians, 'democracy' is not synonymous with 'liberal democracy'; they prioritize elected incumbents' power over horizontal

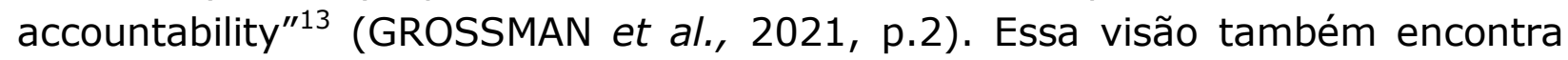
semelhanças com aquilo que se convencionou chamar de democracia iliberal (MOUNK, 2019).

A outra divisão aqui analisada será a econômica, geralmente ancorada por divisões como: auxílio dos governos aos pobres, combate ao desemprego e meritocracia, contempladas nos estudos sobre América Latina acima citados (MORENO, 2019; BORNSCHIER, 2013;2020). Os bancos, não permitiram separar tão bem quanto no caso da divisão democrática, mas até onde foi possível, os dados tentaram estabelecer algum nexo teórico.

O quadro 1 sintetiza os rótulos das díades adotadas, tendo em vista as questões selecionadas ${ }^{14}$, dentro do guarda-chuva teórico das divisões democracia e economia.

\footnotetext{
11 Para uma tipologia de democracia ver os trabalhos de Welzel (2013, capítulo 10), de Kirsh e Welzel (2019), Mounk(2019) e Grossman et al. (2021).

12 Tradução livre a partir dos termos majoritarianism e majoritarian em Grossman et al.,2021.

${ }^{13}$ Em tradução livre: "Majoritários permitem tomadas de poder não apesar de seus ideais democráticos, mas por causa deles. Para os majoritários, "democracia 'não é sinônimo de' democracia liberal'; eles priorizam o poder dos ocupantes eleitos sobre a responsabilidade horizontal".

${ }^{14}$ Constam na tabela 2
}

Caderno Eletrônico de Ciências Sociais, Vitória, v. 9, n. 1, pp. 112-138, 2021 
Quadro 1: Díades selecionadas por banco de dados

\begin{tabular}{|c|c|c|}
\hline Banco de dados & Divisão Econômica & Divisão Democrática \\
\hline Lapop & + estado / - estado & + autoritário / + democracia \\
\hline WVS & + igualitário / - igualitário & $\begin{array}{c}\text { + confiança nas instituições / - confiança } \\
\text { nas instituições }\end{array}$ \\
\hline ESEB & $\begin{array}{c}\text { + meritocrático / - } \\
\text { meritocrático }\end{array}$ & + majoritário / - majoritário \\
\hline
\end{tabular}

Fonte: elaborado pelo autor

Optou-se nesse trabalho, por questões de escopo, abdicar nesse momento de uma possível divisão em issues culturais (Silva 2017a) ou em issues de lei e ordem (Rennó, 2020). Convém, entretanto, ressaltar que futuramente as técnicas aqui utilizadas também podem ser úteis para analisar essas divisões no público.

O foco na análise da situação de partidários de legendas políticas também foge do escopo desse trabalho, a análise aqui tão somente aponta a divisão com base em issues de natureza econômica e democrática.

\section{Dados e métodos}

Inicialmente foram selecionadas variáveis quantitativas ${ }^{15}$ de opinião pública que fossem similares às de Moreno (2019). O quadro 2 contém as questões selecionadas. Para facilitar os objetivos aqui priorizados, a seleção de questões contemplou dois dos três fatores pressupostos por Moreno. Os rótulos inicialmente pensados, visando a AFC, para as questões selecionadas são 'DEMOCRACIA' e 'ECONOMIA'.

Quadro 2: variáveis utilizadas

\begin{tabular}{|l|l|l|l|}
\hline Código & Pergunta & $\begin{array}{l}\text { Rótul } \\
\text { o AFC }\end{array}$ & Base \\
\hline REDIST1 & O governo deve gastar mais na ajuda aos pobres? & ECON & Lapop2019 \\
\hline ROS4 & $\begin{array}{l}\text { O Estado brasileiro deve implementar políticas firmes } \\
\text { para reduzir a desigualdade de renda entre ricos e } \\
\text { pobres. Até que ponto concorda ou discorda desta } \\
\text { frase? }\end{array}$ & ECON & Lapop2019 \\
\hline REDIST3 & $\begin{array}{l}\text { A maioria dos desempregados poderia encontrar um } \\
\text { trabalho se quisessem. Até que ponto concorda ou } \\
\text { discorda desta frase? }\end{array}$ & ECON & Lapop2019 \\
\hline $\begin{array}{l}\text { BRAPARA } \\
\text { P1 }\end{array}$ & $\begin{array}{l}\text { Até que ponto o sr./sra. aprova o direito do PT } \\
\text { concorrer nas eleições? }\end{array}$ & DEM & Lapop2019 \\
\hline
\end{tabular}

${ }^{15}$ Consta na tabela $\mathrm{A} 1$ no apêndice, a distribuição de cada uma das variáveis.

16 A escolha pelo Partido dos Trabalhadores (PT) se deu tendo em base que esse é a legenda política que mais divide os brasileiros (FUKS, RIBEIRO e BORBA, 2021)

Caderno Eletrônico de Ciências Sociais, Vitória, v. 9, n. 1, pp. 112-138, 2021 


\begin{tabular}{|c|c|c|c|}
\hline D1 & $\begin{array}{l}\text { Existem pessoas que sempre falam mal da forma de } \\
\text { governo do Brasil, não somente do governo atual, } \\
\text { mas sim da forma de governo. O quanto o (a) sr./sra. } \\
\text { aprova ou desaprova o direito de votar dessas } \\
\text { pessoas? }\end{array}$ & DEM & Lapop2019 \\
\hline $\mathrm{D} 2$ & $\begin{array}{l}\text { O quanto o(a) sr./sra. aprova ou desaprova que estas } \\
\text { pessoas, que sempre falam mal da forma de governo, } \\
\text { realizem manifestações pacíficas com o propósito de } \\
\text { expressar seus pontos de vista? }\end{array}$ & DEM & Lapop2019 \\
\hline Q106 & Igualdade de renda vs grandes diferenças de renda & ECON & WVS \\
\hline Q108 & $\begin{array}{l}\text { Responsabilidade do governo } \times \text { responsabilidade } \\
\text { individual }\end{array}$ & ECON & WVS \\
\hline Q110 & Sucesso: trabalho duro vs sorte & ECON & WVS \\
\hline Q224 & $\begin{array}{l}\text { Com que frequência nas eleições do país: os votos } \\
\text { são contados de forma justa }\end{array}$ & DEM & WVS \\
\hline Q229 & $\begin{array}{l}\text { Com que frequência nas eleições do país: os } \\
\text { funcionários eleitorais são justos }\end{array}$ & DEM & WVS \\
\hline Q72 & Confiança: Partidos Políticos & DEM & WVS \\
\hline P11b & $\begin{array}{l}\text { O(a) sr(a) concorda ou discorda com a seguinte } \\
\text { afirmação: "Quando alguns acumulam riqueza, isto } \\
\text { ocorre à custa de outros". }\end{array}$ & ECON & ESEB \\
\hline P11c & $\begin{array}{l}\text { O(a) sr(a) concorda ou discorda com a seguinte } \\
\text { afirmação: "Em qualquer situação as pessoas mais } \\
\text { pobres devem ter mais chances do que as ricas". }\end{array}$ & ECON & ESEB \\
\hline P18 & $\begin{array}{l}\text { O(a) sr(a) concorda ou discorda com a seguinte } \\
\text { afirmação: "Quando o Supremo Tribunal Federal } \\
\text { (STF) interfere no trabalho do governo, o Presidente } \\
\text { ou o Congresso podem ignorar o STF". }\end{array}$ & DEM & ESEB \\
\hline Q5b & $\begin{array}{l}\text { O(a) sr(a) concorda ou discorda com a seguinte } \\
\text { afirmação: "A vontade da maioria deveria sempre } \\
\text { prevalecer, mesmo que prejudique os direitos das } \\
\text { minorias". }\end{array}$ & DEM & ESEB \\
\hline Q4e & $\begin{array}{l}\text { O(a) sr(a) concorda ou discorda com a seguinte } \\
\text { afirmação: "Ter um líder forte no governo é bom para } \\
\text { o Brasil mesmo que o líder não cumpra as regras para } \\
\text { fazer as coisas". }\end{array}$ & DEM & ESEB \\
\hline
\end{tabular}

Fonte: Lapop 2019, WVS 2018 e ESEB 2018

$\mathrm{Na}$ coluna Rótulo AFC são designadas a expectativa quanto a quais divisões comporão cada fator. Essas expectativas consolidam em três hipóteses desse trabalho:

H3 - REDIST1, ROS4 e REDIST3 serão reduzidas a um fator, já as variáveis, BRAPARAP1, D1 e D2, a outro.

H4 - Q106, Q108 e Q110 serão reduzidos a um fator, já as variáveis Q224, Q229 e Q72, a outro

H5 - P11b e P11c serão reduzidos a um fator, já as variáveis $P 18, Q 5 b$ e Q5e, a outro.

Foram removidas as não respostas tendo permanecido 1448 respostas das 1498 da amostra inicial do Lapop, sendo esse um dos critérios da seleção das questões, uma vez que além de se assemelharam às selecionadas por

Caderno Eletrônico de Ciências Sociais, Vitória, v. 9, n. 1, pp. 112-138, 2021 
Moreno (2019) e Bornschier (2013;2020), não terem gerado perda excessiva de dados. No que concerne à análise com dados do WVS, após a remoção das não respostas, foram 1226 respostas disponibilidades. Entre os dados do ESEB, foram 1950 respostas analisadas.

As questões selecionadas na dimensão econômica dialogam com as usadas em outros estudos, como já citados. Da mesma forma que as questões pensadas como da dimensão democráticas incorporaram dimensões que favorecem pressupostos basilares mínimos de democracia liberal.

O software utilizado nessa análise é $O R^{17}$. $O$ apêndice ao fim desse trabalho contém matrizes de correlação e os screeplots. Os scripts utilizados podem ser obtidos via contato com o autor.

Antes de apresentar os resultados, cumpre algumas observações metodológicas. A primeira dela diz respeito a normalidade das variáveis. Esta não é uma exigência, mas segundo Reis (2019), é aconselhável. Então optouse por fazer com todas as variáveis normalizadas ${ }^{18}$, os resultados dessa análises são similares aos encontrados nas análises aqui discutidas.

No que concerne ao padrão de correlação entre as variáveis, a matriz de correlações deve exibir o teste de Kaiser-Meyer-Olklin (KMO) varia entre 0 e 1. Quanto mais perto de 1, tanto melhor (FIGUEIREDO; FILHO, 2010). Reis (2019) aponta que acima de 0,5 é considerado aceitável. Seguindo, Figueiredo e Filho (2010) a estatística Bartelett Test of Spherecity (BTS) deve ser estatisticamente significante $(p<0,05)$.

A fim de reduzir as informações presentes nas variáveis originais, deve-se reduzir o número de fatores. Na literatura, diversos processos são sugeridos: determinação a priori, observação dos autovalores, representação gráfica (screeplot), testes de significância entre outros. Optou-se, para PCA, pela screeplot e autovalores. A escolha se deu por serem essas, técnicas indicadas por Matos e Rodrigues (2019). Para AFC, determinou-se a priori, com base em expectativa teórica, mas para essa técnica também foram gerados testes de screeplot e autovalores. Seguindo Figueiredo e Filho (2010) optou-se pelo método de rotação ortogonal Varimax tanto para AFC, quanto para PCA.

Para proceder a comparação mencionada na segunda hipótese, serão dois os métodos. O primeiro é dos autovalores. Seguindo Matos e Rodrigues (2019) e Figueiredo e Filho (2010) buscar-se-á verificar se os fatores escolhidos por

\footnotetext{
$17<$ http://rstudio.com/>

18 Abdi, Willians e Valentin (2013) dizem ser possível proceder a PCA com variáveis normais, por isso a tentativa.
}

Caderno Eletrônico de Ciências Sociais, Vitória, v. 9, n. 1, pp. 112-138, 2021 
cada técnica apresentam autovalores maiores do que 1. Outra comparação será relacionada ao root mean square of the residuals ${ }^{19}$ (doravante, RMSR). Quanto mais próximo de zero, melhor desempenho.

Convém ressaltar, entretanto, que não há muita concordância em relação ao RMSR(Shevlin, Miller e Lewis, 1999). Preacher e MacCallum (2002) julgam que valores até 0,10 são adequados. Ruscio e Roche (2012) apontam que valores menores indicam melhor modelo. Tendo em base os dois estudos, vamos comparar PCA e AFC, feita a ressalva que essa medida é menos consensual do que os autovalores.

O autovalor maior que 1 , por outro lado, é um critério adotado na maior parte dos trabalhos (Matos e Rodrigues, 2019) em especial na área (Dalton, 2018). Embora Fabrigar et al., (1999) não tenha concordância quanto a esse limite em seu levantamento de estudos psicométricos.

O root mean square error of approximation ${ }^{20}$ (doravante, RMSEA) é uma medida que também será avaliada aqui. Essa é uma medida, utilizada somente na AFC é, segundo Silva (2017a), adequada se apresentar valores menores que 0,05 .

\title{
Resultados
}

Iniciamos essa seção com a apresentação dos resultados dos dados do Lapop 2019. O primeiro passo seguindo o aconselhamento de Reis (2019) é gerar uma matriz de correlação, afim de que se possa ter um primeiro vislumbre do relacionamento das variáveis. A matriz gerada foi apresentada na figura 1.

Para que a análise fatorial seja adequada, as variáveis devem ser correlacionadas. Espera-se também que as variáveis altamente correlacionadas umas com as outras se correlacionem também com o(s) mesmo(s) fatore(s). Para proceder essa verificação são necessários dois passos:

\begin{abstract}
"Para testar a conveniência do modelo fatorial pode-se aplicar o teste de esfericidade de Bartlett para testar a hipótese nula, de que as variáveis não sejam correlacionadas na população. Um valor elevado da estatística de teste favorece a rejeição da hipótese nula. Também, a medida de adequacidade da amostra de Kaiser-Meyer-Olkin (KMO) compara as magnitudes dos coeficientes de correlação observados com as magnitudes dos coeficientes de correlação parcial. Pequenos valores de $\mathrm{KMO}$ indicam que as correlações entre os pares de variáveis não podem ser explicadas por outras variáveis, indicando que a análise fatorial não é adequada" (Reis, 2019, on-line).
\end{abstract}

\footnotetext{
${ }^{19}$ Raiz quadrada média dos resíduos, em tradução livre.

${ }^{20}$ Raiz quadrada média do erro de aproximação, em tradução livre.
}

Caderno Eletrônico de Ciências Sociais, Vitória, v. 9, n. 1, pp. 112-138, 2021 
No primeiro teste, o de esfericidade de Bartlett, busca-se verificar se "a matriz de correlação da população é uma matriz identidade, ou seja, as variáveis não são correlacionadas na população" (Ibidem). Ou "[...] se a matriz de correlação da população não é uma matriz identidade, ou seja, as variáveis são correlacionadas na população" (Ibidem). Para continuar deve-se obter a segunda.

O resultado encontrado foi satisfatório, ou seja, de a hipótese nula de que a matriz de correlação da população seja uma matriz identidade é rejeitada pelo teste de esfericidade de Bartlett. A estatística qui-quadrado aproximada é 404,38 com 15 graus de liberdade, significativa ao nível de 0,05. A estatística KMO com todas as variáveis maiores do que 0,5 também concorda quanto ao fato de que a análise fatorial (seja AFC ou PCA) pode ser considerada uma técnica apropriada para analisar a matriz de correlação. $O$ que foi feito até aqui era conjunto. Agora as análises de AFC e PCA se dão de forma separada ${ }^{21}$.

$\mathrm{Na}$ análise do método screeplot foram escolhidas 2 fatores ${ }^{22}$ para PCA (o mesmo já pré-selecionado para AFC). A tabela 1 reporta os resultados para PCA e AFC para matriz rotada com método varimax:

Tabela 1: Análise dos Componentes Principais e Análise Fatorial Confirmatória com matriz rotada no método Varimax, Brasil, Lapop 2019.

\begin{tabular}{|c|c|c|}
\hline \multicolumn{3}{|c|}{ PCA Lapop 2019 - 6 questões } \\
\hline & $\begin{array}{c}10 \text { fator } \\
\text { Democracia }\end{array}$ & $\begin{array}{l}20 \text { fator } \\
\text { Economia }\end{array}$ \\
\hline REDIST1 - Ajuda aos pobres & & 0,72 \\
\hline ROS4 - Políticas combate redução desigualdade & & 0,63 \\
\hline REDIST3 - Desemprego é falta de vontade & & 0,62 \\
\hline BRAPARAP1 - Direito do PT & 0,42 & \\
\hline D1 - Direito de voto de quem sempre critica o governo & 0,74 & \\
\hline $\begin{array}{l}\text { D2 - Direito de manifestação pacífica de quem sempre } \\
\text { crítica o governo }\end{array}$ & 0,78 & \\
\hline Eingenvalues & 1,58 & 1,20 \\
\hline \multicolumn{3}{|l|}{ RMSR: 0,16} \\
\hline \multicolumn{3}{|c|}{ AFC Lapop 2019 - 6 questões } \\
\hline & $\begin{array}{c}10 \text { fator } \\
\text { Democracia }\end{array}$ & $\begin{array}{c}20 \text { fator } \\
\text { Economia }\end{array}$ \\
\hline REDIST1 - Ajuda aos pobres & & 0,55 \\
\hline ROS4 - Políticas combate redução desigualdade & & 0,38 \\
\hline REDIST3 - Desemprego é falta de vontade & & 0,26 \\
\hline
\end{tabular}

21 Para diferenciar o tipo de análise fatorial basta diferenciar na função 'princomp' a atribuição 'cor'. Sendo TRUE para análise da matriz de correlação útil para PCA e 'FALSE' para análise da matriz de covariância útil para AFC. (REIS, 2019, on-line). Outra mudança também se dá na rotação varimax, onde o comando 'principal' refere-se à PCA e o comando 'fa' refere-se à AFC.

${ }^{22}$ Os screeplots de todas as análises constam no apêndice.

Caderno Eletrônico de Ciências Sociais, Vitória, v. 9, n. 1, pp. 112-138, 2021 


\begin{tabular}{l|c|c}
\hline BRAPARAP1 - Direito do PT & 0,18 & \\
\hline D1 - Direito de voto de quem sempre critica o governo & 0,49 & \\
\hline $\begin{array}{l}\text { D2 - Direito de manifestação pacífica de quem sempre } \\
\text { crítica o governo }\end{array}$ & 0,73 & 0,46 \\
\hline Eigenvalues & 0,92 & \\
\hline \multicolumn{2}{c}{ RMSR: 0,03 e RMSEA: 0,026 a $90 \%$} \\
\hline
\end{tabular}

Fonte: Elaborado pelo autor a partir de dados do Lapop 2019

Nesta fase da PCA é usual tentar dar nomes aos fatores: Fator 1: Democracia; Fator 2: Economia.

Com os dois fatores encontrados e rotulados, podemos concluir que os achados de PCA são semelhantes aos da AFC no que concerne a expectativa prévia de fatores. Logo, há então a confirmação de $\mathrm{H} 1$ para os dados do Lapop. Concomitante a isso, como não é de surpreender, H3 também é corroborado pelos dados dessa base.

Uma pergunta oportuna seria de como interpretar os fatores? "Com cargas fatoriais em torno de 0,80, obtêm-se soluções fatoriais altamente estáveis em amostras de 50 pessoas. Quando as cargas fatoriais estão ao redor de 0,40, porém, amostras de 300 a 400 sujeitos são necessárias para atingir soluções estáveis" (LAROS, 2005, p. 170). Já que dispomos de um bom número de casos, podemos considerar os fatores como dignos de análise. Complementa essa informação o fato de que para análises exploratórias como a PCA, com carga mínima de 0,30, "[...]é considerado uma carga mínima necessária para a variável ser um representante útil do fator" (Ibidem, p.186). Em todas nossas análises, os fatores para PCA mostraram-se acima desse limiar.

No que concerne a segunda hipótese essa só parcialmente verdadeira até aqui já que PCA se mostrou melhor ajustado quando considerado os autovalores. Levando em consideração a mais controversa medida RMSR, a AFC parece ter melhor ajuste. 
Imagem 1: Distribuição dos casos entre os fatores encontrados PCA e AFC, Brasil, Lapop 2019

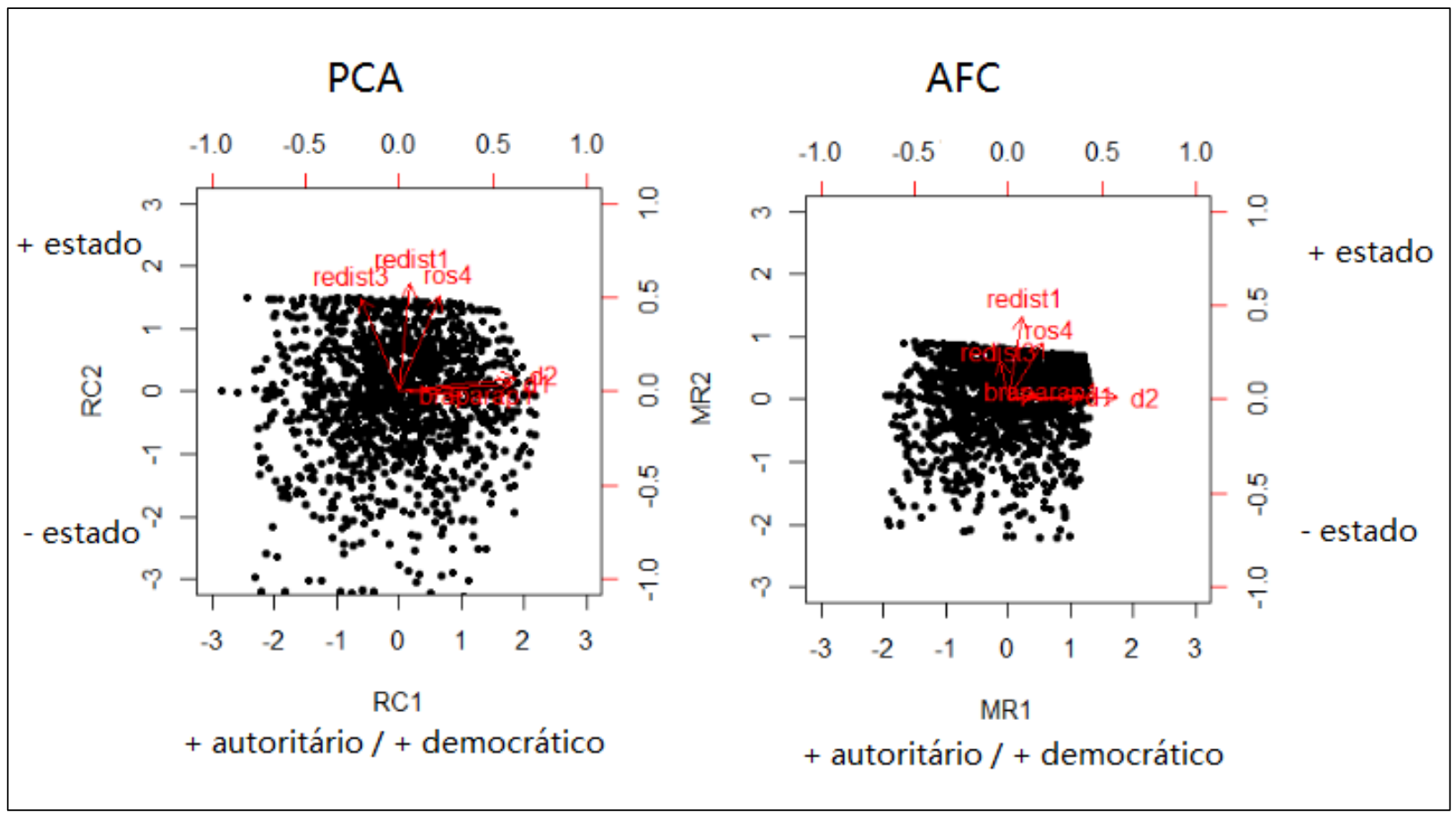

Fonte: elaborado pelo autor a partir do LAPOP 2019

A fim de comparar melhor as duas técnicas a imagem 1 apresenta o 'biplot' da PCA e da AFC. O biplot, gerado no software estatístico através do pacote "psych", delimita os dados da amostra dentro dos fatores criados

Convém relembrar, conforme exposto na tabela 1, que a nomenclatura escolhida para delimitar o espaço das imagens oriundas de biplots nesse trabalho, seguem a ideia de se assemelharem o mais próximo possível das questões selecionadas. Sem, entretanto, abdicar dos rótulos gerais de democracia e economia definidas previamente como fatores de AFC.

Nota-se a semelhança, por um lado, entre os achados das técnicas de extração de fatores. Por outro, nota-se a maior dispersão gerada pelo PCA.

Dando prosseguimento, vamos agora apresentar os resultados tendo como base os dados selecionados da WVS. No que concerne ao teste de esfericidade Bartlett, a análise com a base do WVS mostrou a estatística quiquadrado aproximada de 334,22 com 15 graus de liberdade, significativa ao nível de 0,05. A estatística KMO se mostrou apropriada com valores acima de 0,5 para todas as variáveis ${ }^{23}$.

${ }^{23}$ A matriz de correlação da análise contendo dados da WVS consta na imagem A4 no apêndice $A$.

Caderno Eletrônico de Ciências Sociais, Vitória, v. 9, n. 1, pp. 112-138, 2021 
$\mathrm{Na}$ análise do método screeplot com os dados da $\mathrm{WVS}^{24}$ também foram escolhidos 2 fatores para PCA (o mesmo já pré-selecionado para AFC). A tabela 2 reporta os resultados para PCA e AFC para matriz rotada com método varimax:

Tabela 2: Análise dos Componentes Principais e Análise Fatorial Confirmatória com matriz rotada no método Varimax, Brasil, WVS 2018.

\begin{tabular}{|c|c|c|}
\hline \multicolumn{3}{|c|}{ PCA WVS 2018 - 6 questões } \\
\hline & 10 fator Democracia & 20 fator Economia \\
\hline $\begin{array}{l}\text { Q106 - Igualdade de renda v.s grandes } \\
\text { diferenças } \\
\text { Q108 - Responsabilidade individual ou } \\
\text { do governo } \\
\text { Q110 - Trabalho duro ou sorte }\end{array}$ & & $\begin{array}{l}0,654 \\
0,756 \\
0,568\end{array}$ \\
\hline $\begin{array}{l}\text { Q224 - Eleições: voto contado de } \\
\text { forma justa? } \\
\text { Q229 - Eleições: funcionários eleitorais } \\
\text { justos? } \\
\text { Q72 - Confiança: Partidos Políticos }\end{array}$ & $\begin{array}{l}0,780 \\
0,713 \\
0,582 \\
\end{array}$ & \\
\hline Eingenvalues & 1,49 & 1,31 \\
\hline \multicolumn{3}{|c|}{ RMSR: 0,17} \\
\hline \multicolumn{3}{|c|}{ AFC WVS 2018 - 6 questões } \\
\hline & 10 fator Democracia & $2^{\circ}$ fator Economia \\
\hline $\begin{array}{l}\text { Q106 - Igualdade de renda v.s grandes } \\
\text { diferenças } \\
\text { Q108 - Responsabilidade individual ou } \\
\text { do governo } \\
\text { Q110 - Trabalho duro ou sorte }\end{array}$ & & $\begin{array}{l}0,287 \\
0,754 \\
0,244\end{array}$ \\
\hline $\begin{array}{l}\text { Q224 - Eleições: voto contado de } \\
\text { forma justa? } \\
\text { Q229 - Eleições: funcionários eleitorais } \\
\text { justos? } \\
\text { Q72 - Confiança: Partidos Políticos }\end{array}$ & $\begin{array}{l}0,737 \\
0,445 \\
0,313\end{array}$ & \\
\hline Eigenvalues & 0,86 & 0,69 \\
\hline
\end{tabular}

Fonte: elaborado pelo autor a partir de dados do WVS 2018

Os achados são similares aos encontrados na análise do Lapop, em especial ao fato de a divisão econômica ser apontada como segundo fator em ordem de importância nas duas análises. H1 e H4 são confirmadas. E sobre H2, o mesmo "impasse" se mantém. Ou seja, o melhor desempenho da PCA nos autovalores e da AFC no RMSR. Também foi possível transpor - na imagem 2 as posições dos respondentes dentro dos fatores para a análise do WVS.

${ }^{24}$ Consta no apêndice $A$

Caderno Eletrônico de Ciências Sociais, Vitória, v. 9, n. 1, pp. 112-138, 2021 
Imagem 2: Distribuição dos casos entre os fatores encontrados PCA e AFC, Brasil, WVS 2018

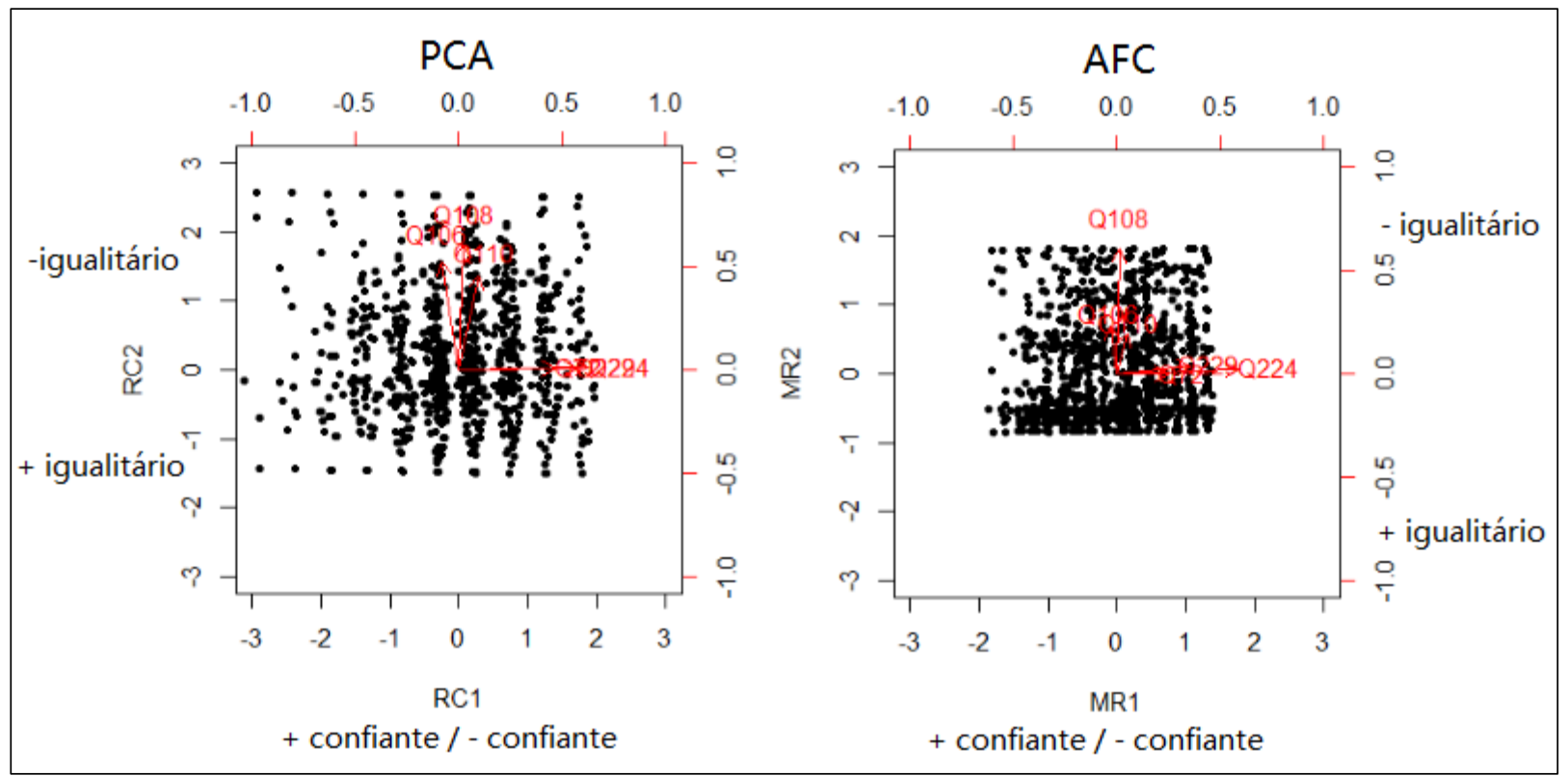

Fonte: elaborado pelo autor a partir da WVS 2018

Por fim, cumpre apresentar os resultados encontrados com os dados do ESEB. Em primeiro lugar, é mister apontar que a estatística BTS para dados do ESEB foi de 343,88 com 10 graus de liberdade, significativa ao nível de 0,05. A estatística KMO também se mostrou apropriada para analisar a matriz de correlação. A tabela 3 apresenta os resultados de PCA e AFC para os dados do ESEB: 
Tabela 3: Análise dos Componentes Principais e Análise Fatorial Confirmatória com matriz rotada no método Varimax, Brasil, ESEB 2018.

\begin{tabular}{|c|c|c|}
\hline \multicolumn{3}{|c|}{ PCA ESEB $2018-6$ questões } \\
\hline & $\begin{array}{l}10 \text { fator } \\
\text { Democracia }\end{array}$ & 20 fator Economia \\
\hline $\begin{array}{l}\text { P11b - Mérito da riqueza? } \\
\text { P11c - Mais chances aos pobres? }\end{array}$ & & $\begin{array}{l}0,81 \\
0,72\end{array}$ \\
\hline $\begin{array}{l}\text { P18 Presidente pode ignorar STF e } \\
\text { congresso? }\end{array}$ & & \\
\hline $\begin{array}{l}\text { Q5b A vontade da maioria deve } \\
\text { prevalecer? }\end{array}$ & 0,73 & \\
\hline $\begin{array}{l}\text { Q4e Líder forte, mesmo que não } \\
\text { cumpra as regras? }\end{array}$ & 0,73 & \\
\hline Eingenvalues & 1,51 & 1,09 \\
\hline
\end{tabular}

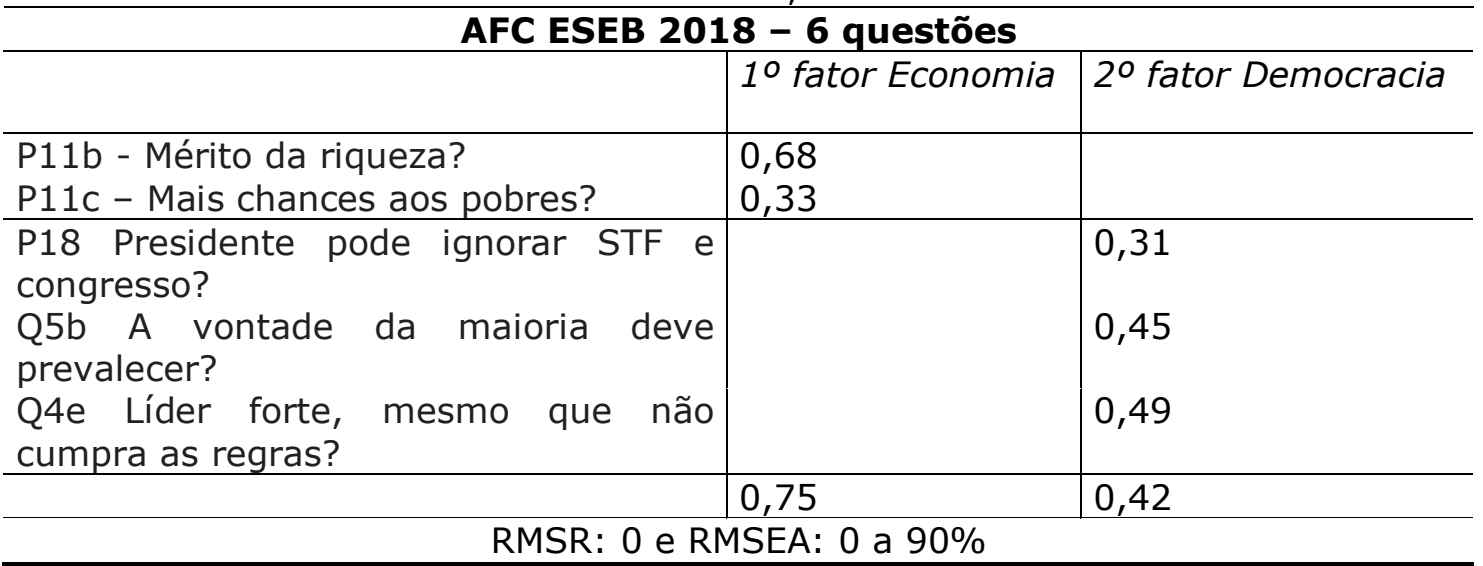

Fonte: elaborado pelo autor a partir de dados do ESEB 2018

$\mathrm{Na}$ PCA, as questões atinentes à democracia apareceram como fator $1^{\circ} \mathrm{e}$ a economia como 20 , já na AFC a ordem se inverteu. Embora esse fato não negue $\mathrm{H} 1$, é de se notar que pela primeira vez na análise há uma diferença significativa entre a escolha entre duas técnicas de extração de fatores. H5, também é confirmado. Uma vez que a ordem dos fatores é diversa para AFC e PCA, os biplots devem ser apresentados em imagens separadas.

No caso da PCA (imagem 3), percebemos que as variáveis de mensuração econômica seguem o padrão esperado. No caso das variáveis da divisão democrática, duas das três seguem padrão esperado (Q4e e Q5b), já P18 tem sentido ligeiramente diagonal que aponta que não se encaixa no mesmo padrão totalmente, o menor valor de 0,52 (apontado na tabela 5) para essa variável pode indicar que não é tão forte. Convém lembrar que o ESEB é anterior ao mandato de Jair Bolsonaro, onde os questionamentos acerca do STF foram crescentes $^{25}$.

25 Bolsonaristas ameaçam invadir STF e Congresso com apoio de militares da reserva. Disponível em: <https://congressoemfoco.uol.com.br/governo/bolsonaristas-ameacaminvadir-stf-e-congresso-com-apoio-de-militares-da-reserva/> Acesso em 05 ago. 2021.

Caderno Eletrônico de Ciências Sociais, Vitória, v. 9, n. 1, pp. 112-138, 2021 
NA AFC o mesmo padrão "errático" de P18 também foi constatado. Na divisão econômica, $\mathrm{P} 11 \mathrm{c}$ teve indicação frágil quanto ao pertencimento à díade da meritocracia.

Completa-se essa análise mencionando que a criação de fatores pode ser útil, pois pode ser utilizada a posteriori como variável em modelos de regressão dos mais variados tipos associação às variáveis de controle usuais. Esse procedimento foi utilizado em análises supracitadas como as de Dalton (2018) e Moreno (2019).

Imagem 3: Distribuição dos casos entre os fatores encontrados PCA, Brasil, ESEB 2018

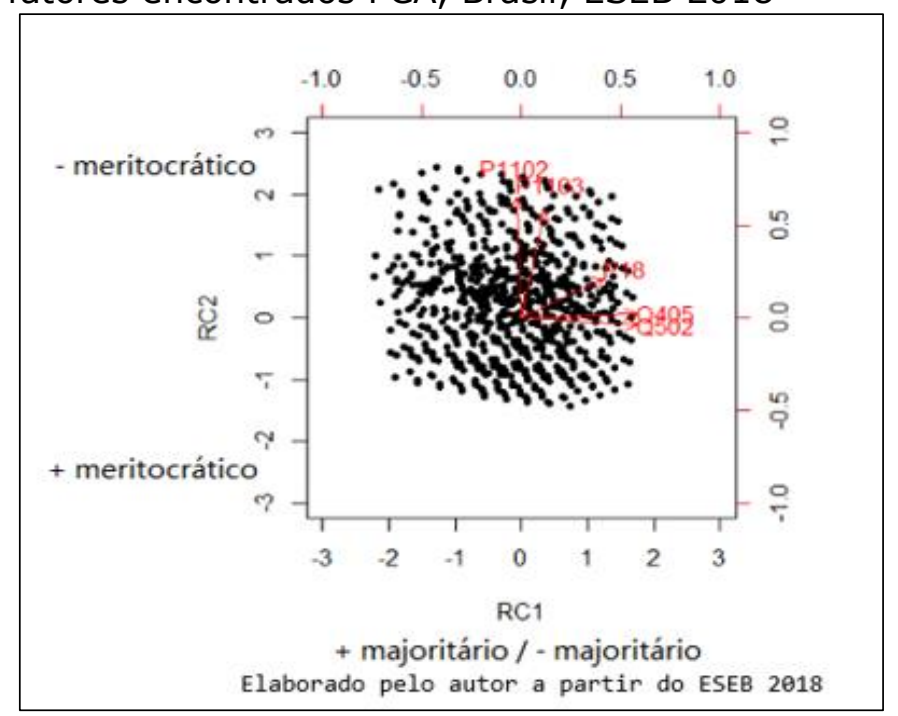

Fonte: elaborado pelo autor 
Imagem 4: Distribuição dos casos entre os fatores encontrados AFC, Brasil, ESEB 2018

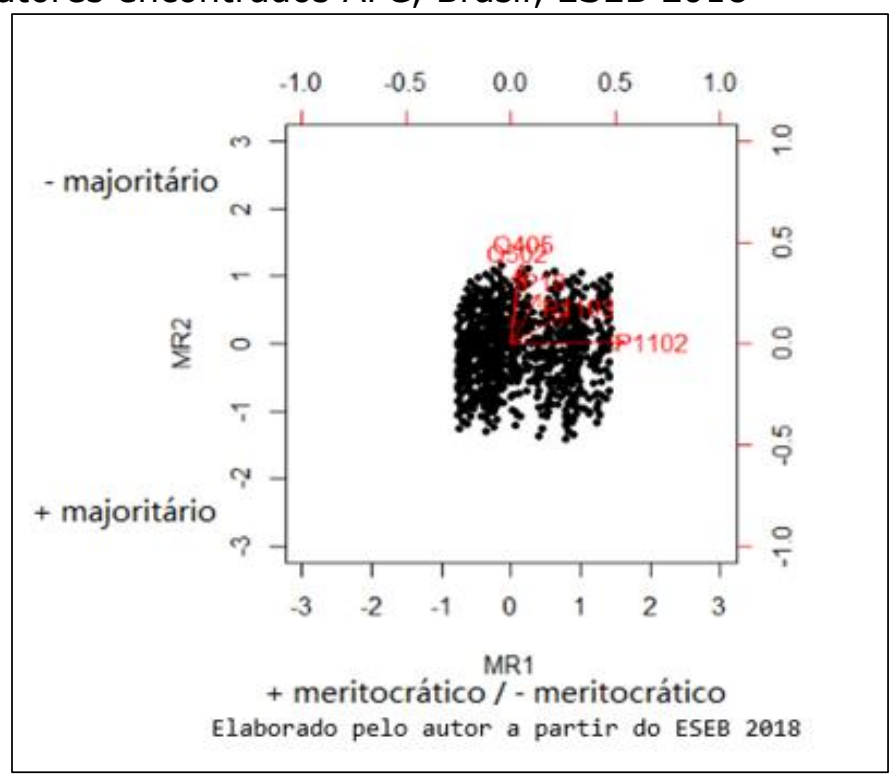

Fonte: elaborado pelo autor

\section{Discussão e conclusão}

Uma primeira observação é atinente aos valores dos fatores observados nas análises. Uma vez AFC trabalha com a variância partilhada dos itens (variância erro e variância única são excluídas) e PCA com a variância total observada, é de se esperar que os valores apontados nessas tabelas sejam maiores para PCA. Isso, entretanto, não indica melhor ajuste para uma ou outra técnica. Somente que PCA é menos exigente. (FABRIGAR et al., 1999).

Em relação à hipótese 1 , ocorreu a confirmação. Uma vez que, os resultados de AFC e PCA, tanto para os dados são similares no que concerne ao número de fatores e questões localizados em cada fator. Fabrigar et al. (1999) chama atenção em seu estudo sobre essa dimensão, logo é interessante notar que com dados de natureza diversa, o fato tenha se repetido. A única observação em relação à essa dimensão foi que na análise dos dados do ESEB, as duas técnicas destacaram ordens de importância diferentes para os fatores.

Houve também a confirmação das hipóteses 3,4 e 5. Isso significa que a seleção prévia das questões, base para o constructo da AFC, também se mostrou válida na PCA.

A segunda hipótese, entretanto, não totalmente corroborada nos dados. Os autovalores maiores que 1 somente se deram no caso da PCA. Embora, convém lembrar, que a na medida mais controversa RMSR a "vantagem" seja do AFC.

\footnotetext{
"Quanto mais confiáveis as variáveis a serem analisadas, mais equivalentes são os resultados dos dois métodos de análise fatorial. A mesma lógica aplica-se em relação ao número de variáveis que entra
} 
numa análise fatorial; quanto mais variáveis entram, mais equivalentes os resultados da análise dos componentes principais e análise fatorial."(LAROS, 2005, p.182).

Tendo em base essa citação, é possível que uma seleção mais aprofundada e completa dos dados obtivesse um desempenho mais similar entre as duas técnicas.

Em relação aos achados reportados na imagem 1, há ainda de se mencionar um caso que merece especial menção, REDIST3:

REDIST3 no Lapop 2019 pergunta: "A maioria dos desempregados poderia encontrar um trabalho se quisessem. Até que ponto concorda ou discorda desta frase?". Sendo que: 1 é "discorda muito"; 7 é "concorda muito".

Essa questão, não teve sua direção apontada no sentido esperado (flecha vermelha para baixo), ou seja, a concordância com a posição menos estatizante foi no sentido contrário às outras questões que compuseram o fator econômico para Lapop. Isso posto, julga-se que este fato talvez tenha se dado pela conotação moral que essa questão levanta. Uma vez que, que as outras duas não tinha esse mesmo direcionamento. Talvez o uso de outras questões pudesse ter apontado em outra direção. REDIST3 parece ser mais condizente com a díade + meritocrático/- meritocrático utilizada como base da divisão econômica nos dados do ESEB.

Isso posto, denota que a grande questão na análise das clivagens que dividem o público se dá na seleção de questões que serão avaliadas para compor os fatores. No entanto, dado que o objetivo primordial desse trabalho era o de comparar duas técnicas de extração de fatores, o apontamento referente à REDIST3 não deve preocupar aqui.

Para avançar além do objetivo principal aqui proposto, a incorporação de mais questões e a possibilidade de se testar AFC e PCA com mais de dois fatores pode ser útil. Em especial a incorporação questões de divisão cultural, como sugeridos por tantos estudos (SILVA, 2017a; 2017b; DALTON, 2018; MORENO 2019; BORNSCHIER 2013;2020). No que concerne ao Brasil, talvez fosse interessante incorporar os achados de Rennó (2020) sobre a pertinência das questões de lei e ordem. Testar um possível fator dessa natureza com o uso de técnicas de extração de fatores como a AFC e PCA poderia gerar notável ganho analítico.

Resultados semelhantes em termos de estrutura fatorial identificados (H1) podem sugerir erroneamente que esses métodos podem ser usados de forma intercambiável. No entanto, esse não é o caso, porque PCA e AFC são

Caderno Eletrônico de Ciências Sociais, Vitória, v. 9, n. 1, pp. 112-138, 2021 
técnicas diferentes que diferem em seus objetivos finais. O PCA explora intercorrelações de itens com o objetivo de reduzir os itens em um conjunto menor de componentes, enquanto o AFC é uma técnica inferencial que testa hipóteses de validade de modelo de medida predefinido. Isso torna o PCA sozinho insuficiente para identificar a complexidade das questões como as aqui testadas, porque é importante ser capaz de realizar alguma forma de teste de hipótese (por exemplo, no impacto de adicionar itens, especificar cargas cruzadas ou especificar variações residuais). No entanto, como a medição de construtos de opinião pública é complexa, o desenvolvimento de escala e os estudos de validação de construto geralmente sugerem AFC apenas depois de ter usado técnicas exploratórias para investigar a estrutura latente de um estudo com mais variáveis. O ideal seria utilizar a técnica de PCA para análises exploratória e o AFC complementando e dando robustez aos achados.

Daí advém a ideia de que não há "vencedores" e "perdedores", e sim técnicas complementares. Estando bem ancorado em teoria, é possível e desejável proceder as duas técnicas. Apesar dessas limitações de cada técnica e da proposição de utilizar apenas poucas questões de cada base de dados, este estudo constitui um importante esforço na medida em que esclarece que PCA e AFC podem ser usados para identificar fatores de opinião pública. Assim se destaca a necessidade de usar os dois métodos de uma maneira integrada para selecionar adequadamente as eventuais divisões existentes no público.

Cumpre por fim destacar, que a obra de Fabrigar et al. (1999), inspiração para nossa análise, é certeira quando aponta a pertinência dos argumentos favoráveis acerca da AFC. No entanto, nosso estudo, não é tão conclusivo. Convém lembrar, entretanto, que os próprios autores do estudo ressalvam que tais condições dependem muito das premissas teóricas que antecedem a análise. Os processos de redução de dados em estudos acadêmicos tem essa exigência, que é o estar ancorado em premissas teóricas que condicionem as técnicas a serem utilizadas;

\section{Referências}

ABDI H.; WILLIAMS L.J.; VALENTIN D. 2013. Multiple factor analysis: principal component analysis for multitable and multiblock data sets: multiple factor analysis. WIREs Comp Stat. volume 5, pp. 149-79.

ALBERTUS, M.; GROSSMAN, G. 2021. "The Americas: When Do Voters Support Power Grabs?" Journal of Democracy, vol. 32, n. 2, pp. 116-131.

BORNSCHIER, Simón. 2013. Trayectorias históricas y «responsiveness» del sistema de partidos en siete países de América Latina. América Latina Hoy, v. 65, pp. 45-77. 
CAMPELLO, D. 2015. Institucionalização Partidária e Consistência Programática: A Resposta da Esquerda a Ataques Especulativos na América Latina. Dados [online]. vol.58, n.2, pp. 427-460.

BORNSCHIER, S. 2019. Historical polarization and representation in South American party systems, 1900-1990. British Journal of Political Science, vol. 49, n. 1 , pp. 153-179

BORNSCHIER, S. 2020. Combining deductive and inductive elements to measure party system responsiveness in challenging contexts: an approach with evidence from Latin America. Eur Polit Sci. 19, pp. 540-549.

DAHL, R. 2006. A preface to democratic theory. Chicago: The University of Chicago Press.

DALTON, R. J. 2018. Political realignment: economics, culture, and electoral change. Oxford: Oxford University Press.

MENDES, G.H.D.S; GANGA, G.M.D. 2013. Predicting Success in Product Development: The Application of Principal Component Analysis to Categorical Data and Binomial Logistic Regression. Journal of Technology Management \& Innovation, Santiago, vol. 8, n. 3, pp. 83-97.

DEEGAN-KRAUSE, Kevin. 2007. New Dimensions of Political Cleavage. In: The Oxford Handbook of Political Behavior. Oxford University Press: New York.

FABRIGAR, L. R., WEGENER, D. T., MACCALLUM, R. C., \& STRAHAN, E. J. 1999. Evaluating the use of exploratory factor analysis in psychological research. Psychological Methods, vol. 4, n. 3, pp. 272-299.

FIGUEIREDO, D. B.; SILVA, J. A. 2010. Visão além do alcance: uma introdução à análise fatorial. Opinião Pública, Campinas, v. 16, n. 1, pp. 160-185,

FINCH, A. P.; BRAZIER, J.E.; MUKURIA, C.; BJORNER, J. 2017. An Exploratory Study on Using Principal-Component Analysis and Confirmatory Factor Analysis to Identify Bolt-On Dimensions: The EQ-5D Case Study, Value in Health, vol. 20, n. 10, pp. 1362-1375.

FUKS, M.; RIBEIRO, E.; BORBA, J. 2021. From Antipetismo to Generalized Antipartisanship: The Impact of Rejection of Political Parties on the 2018 Vote for Bolsonaro. Bras. Political Sci. Rev., São Paulo, v. 15, n. 1, pp. 01-28.

FUKS, M.; MARQUES, P. 2020. Afeto ou ideologia: medindo polarização política no Brasil?. In: $12^{\circ}$ ENCONTRO DA ABCP, 2020, Universidade Federal da Paraíba, João Pessoa (PB). Área Temática: Comportamento Político e Opinião Pública [...]. [S. I.: s. n.]. 
FUKS, M.; MARQUES, P. 2021. Polarização e contexto: explicando a polarização política no Brasil. In: $6^{\circ}$ Workshop Comportamento e Opinião Pública, Universidade Federal de Pernambuco, Recife (PE). [S. I.: s. n.].

GUEDES-NETO, J. V. Voto e identificação partidária em 2018: ordenação social na política brasileira. OPINIÃO PÚBLICA, Campinas, vol. 26, no 3 , pp. 431-451. GROSSMAN, G., KRONICK, D., LEVENDUSKY, M., \& MEREDITH, M. The Majoritarian Threat to Liberal Democracy. Journal of Experimental Political Science, p. 1-10, 2021.

KIRSCH, H.; WELZEL, C. 2019. Democracy Misunderstood: Authoritarian Notions of Democracy around the Globe, Social Forces, vol. 98, n. 1, pp. 59-92. LAROS, J. 2005. O Uso da Análise Fatorial: Algumas Diretrizes para Pesquisadores. Análise fatorial para pesquisadores, LabPAM Saber e Tecnologia, Brasília, pp. 163-193.

LAYTON, M. L.; SMITH, A. E.; MOSELEY, M. W.; COHEN, M. J. 2021. Demographic polarization and the rise of the far right: Brazil's 2018 presidential election. Research \& Politics.

MATOS, D.A.S; RODRIGUES, E. C. 2019. Análise Fatorial. Brasília: ENAP Epub.

MALKA, A.; LELKES, Y.; SOTO, C. J. 2019. Are Cultural and Economic Conservatism Positively Correlated? A Large-Scale Cross-National Test. British Journal of Political Science, vol. 49, n. 3, pp. 1045-1069,

MEULMAN, J. J.; VAN DER KOOIJ,. A.J.; HEISER, W.J. 2004. Principal Components Analysis with Nonlinear Optimal Scaling Transformations for Ordinal and Nominal Data. In: D. Kaplan (ed.), Handbook of Quantitative Methods in the Social Sciences, Newbury Park, CA: Sage Publications, pp. 4970.

MOUNK, Y. O povo contra a democracia. São Paulo: Companhia das Letras, 2019.

MORENO, A. 2019. Political Cleavages: Issues, Parties and the Consolidation of Democracy. London: Routledge. Epub.

MOTA, E. 2020. Bolsonaristas ameaçam invadir STF e Congresso com apoio de militares da reserva. Congresso em foco, 07 mai. Disponível em: <https://congressoemfoco.uol.com.br/governo/bolsonaristas-ameacam-invadirstf-e-congresso-com-apoio-de-militares-da-reserva/> Acesso em: 05 ago. 2021.

PREACHER, K. J.; MACCALLUM, R. C. 2002. Exploratory factor analysis in behavior genetics research: factor recovery with small sample sizes. Behavior genetics, vol. n. 2, pp. 153-161. 
REIS, Denize Ivete. Capítulo 2 Análise Fatorial. Software R: curso avançado, Cerro Largo, 28 de ago. de 2019. Disponível em: <https://smolski.github.io/livroavancado/analisf.html>. Acesso em: 30 de jul. de 2021.

RENNÓ, L. 2020. The Bolsonaro voter: Issue positions and vote choice in the 2018 Brazilian presidential elections. Latin American Politics and Society. Vol. 62 , n. 4, p. 01-23.

RUSCIO, J., \& ROCHE, B. 2012. Determining the number of factors to retain in an exploratory factor analysis using comparison data of known factorial structure. Psychological Assessment, vol. 24, n. 2, pp. 282 292,

SHEVLIN, M.; MILES, J.N.V.; LEWIS, C.A.; 2000. Reassessing the fit of the confirmatory factor analysis of the multidimensional students life satisfaction scale: comments on 'confirmatory factor analysis of the multidimensional Students' Life Satisfaction Scale'. Personality and Individual Differences, vol. 28, n. 1, pp. 181-185,

SILVA, T. M. 2017. Para além de esquerda e direita: a multidimensionalidade das crenças no Brasil contemporâneo (1989-2014). Tese de Doutorado em Ciência Política. Universidade de Brasília, Brasília.

SILVA, T. M. 2017. Direita, volver?! O declínio do conservadorismo no Brasil contemporâneo. Revista Debates, vol. 11, n. 2, p. 9.

SILVA, G. U. L. da. 2021. Proliferar a democracia em tempos de polarização: a abordagem minimalista. Caminhos: Revista on-line, s. p.

WELZEL, C., 2013. Freedom rising: human empowerment and the quest foremancipation. Cambridge: Cambridge University Press.

WOOLDRIDGE, J. M. 2006. Introdução à econometria: Uma abordagem moderna. Thomson Learning. 
APÊNDICE: análise descritiva, matriz de correlação e screeplots

Tabela A1 - Variáveis descritivas

\begin{tabular}{|c|c|c|c|c|c|c|}
\hline Código & Formato & Mínimo & Mediana & Média & Máximo & $\begin{array}{l}\text { Desvio } \\
\text { Padrão }\end{array}$ \\
\hline REDIST1 & $\begin{array}{l}\text { De } 1 \text { a } 7 \text {, sendo } 7 \text { mais pró- } \\
\text { estado }\end{array}$ & 1 & 7 & 5,717 & 7 & 1,76 \\
\hline ROS4 & $\begin{array}{l}\text { De } 1 \text { a } 7 \text {, sendo } 7 \text { mais pró- } \\
\text { estado }\end{array}$ & 1 & 6 & 5,419 & 7 & 1,89 \\
\hline REDIST3 & $\begin{array}{l}\text { De } 1 \text { a } 7 \text {, sendo } 1 \text { mais pró- } \\
\text { estado }\end{array}$ & 1 & 5 & 4,28 & 7 & 2,24 \\
\hline BRAPARAP1 & $\begin{array}{l}\text { De } 1 \text { a } 10 \text {, sendo } 10 \text { mais } \\
\text { democrático }\end{array}$ & 1 & 4 & 4,49 & 10 & 3,51 \\
\hline D1 & $\begin{array}{l}\text { De } 1 \text { a } 10 \text {, sendo } 10 \text { mais } \\
\text { democrático }\end{array}$ & 1 & 7 & 6,54 & 10 & 2,93 \\
\hline D2 & $\begin{array}{l}\text { De } 1 \text { a } 10 \text {, sendo } 10 \text { mais } \\
\text { democrático }\end{array}$ & 1 & 8 & 6,89 & 10 & 3,24 \\
\hline Q106 & $\begin{array}{l}\text { De } 1 \text { a } 10 \text {, sendo } 1 \text { mais } \\
\text { igualitário }\end{array}$ & 1 & 5 & 5,11 & 10 & 3,52 \\
\hline Q108 & $\begin{array}{l}\text { De } 1 \text { a } 10 \text {, sendo } 1 \text { mais } \\
\text { igualitário }\end{array}$ & 1 & 2 & 3,54 & 10 & 3,11 \\
\hline Q110 & $\begin{array}{l}\text { De } 1 \text { a } 10 \text {, sendo } 1 \text { mais } \\
\text { igualitário }\end{array}$ & 1 & 5 & 4,66 & 10 & 3,51 \\
\hline Q224 & $\begin{array}{l}\text { De } 1 \text { a } 4 \text {, sendo } 1 \text { mais } \\
\text { confiante }\end{array}$ & 1 & 3 & 2,62 & 4 & 1,01 \\
\hline Q229 & $\begin{array}{l}\text { De } 1 \text { a } 4 \text {, sendo } 1 \text { mais } \\
\text { confiante }\end{array}$ & 1 & 2 & 2,50 & 4 & 0,91 \\
\hline Q72 & $\begin{array}{l}\text { De } 1 \text { a } 4 \text {, sendo } 1 \text { mais } \\
\text { confiante }\end{array}$ & 1 & 4 & 3,51 & 4 & 0,76 \\
\hline P11b & $\begin{array}{l}\text { De } 1 \text { a } 5 \text {, sendo } 1 \text { mais } \\
\text { meritocrático }\end{array}$ & 1 & 1 & 2,30 & 5 & 1,64 \\
\hline P11c & $\begin{array}{l}\text { De } 1 \text { a } 5 \text {, sendo } 1 \text { mais } \\
\text { meritocrático }\end{array}$ & 1 & 1,5 & 2,38 & 5 & 1,63 \\
\hline P18 & $\begin{array}{l}\text { De } 1 \text { a } 5 \text {, sendo } 1 \text { mais } \\
\text { majoritário }\end{array}$ & 1 & 4 & 3,32 & 5 & 1,63 \\
\hline Q5b & $\begin{array}{l}\text { De } 1 \text { a } 5 \text {, sendo } 1 \text { mais } \\
\text { majoritário }\end{array}$ & 1 & 4 & 3,25 & 5 & 1,66 \\
\hline Q4e & $\begin{array}{l}\text { De } 1 \text { a } 5 \text {, sendo } 1 \text { mais } \\
\text { majoritário }\end{array}$ & 1 & 4 & 3,22 & 5 & 1,67 \\
\hline
\end{tabular}

Fonte: LAPOP 2019, WVS 2018 e ESEB 2018. 
Imagem 1a: Matriz de correlação e screeplot dos dados utilizados no LAPOP 2019

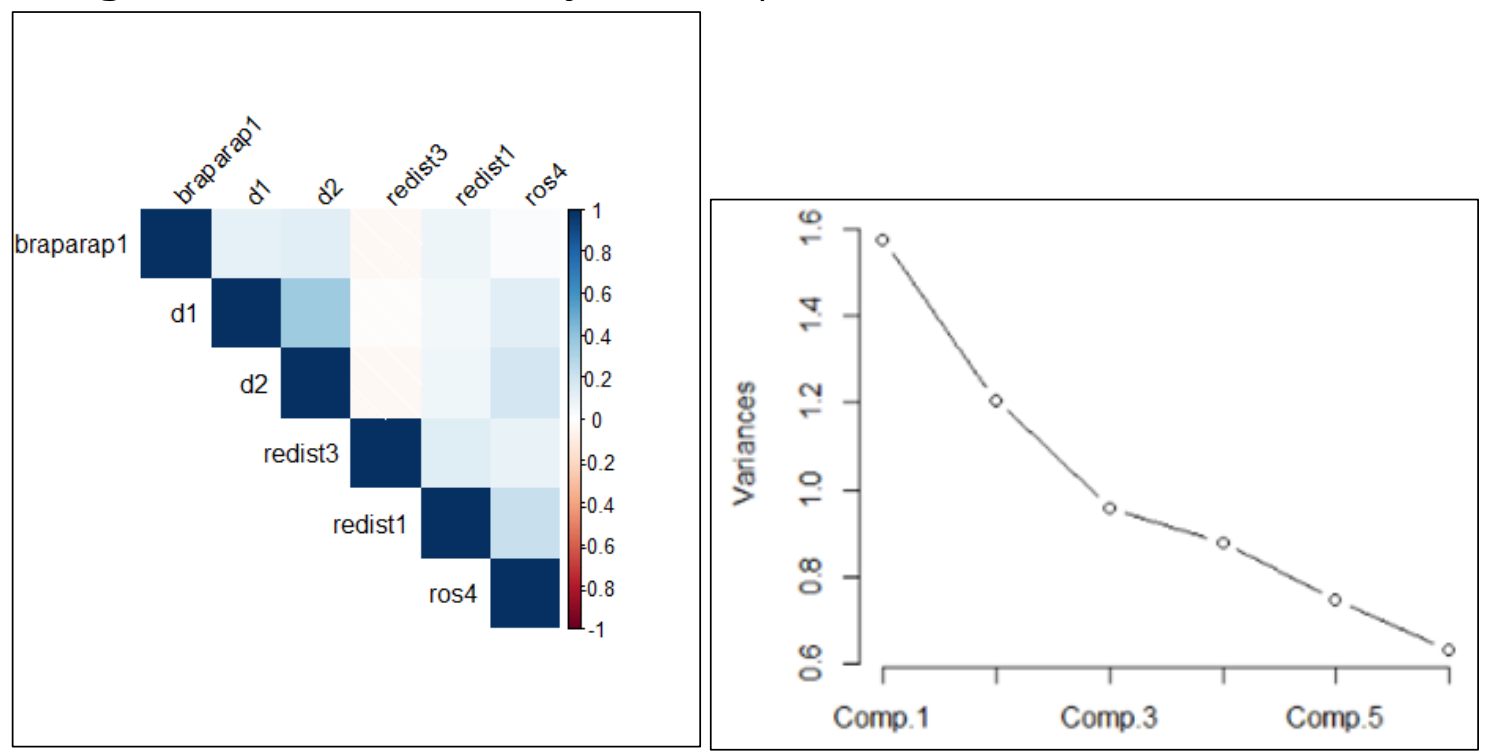

Fonte: elaboração do autor

Imagem A2 - Matriz de correlação e screeplot dos dados utilizados no WVS 2018

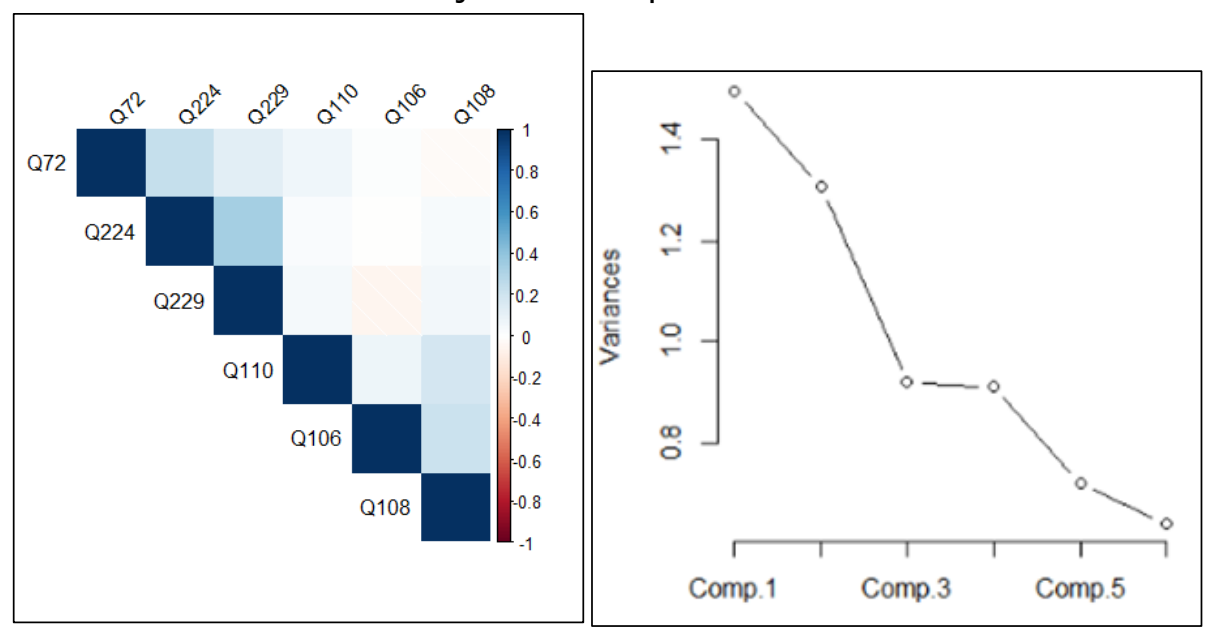

Fonte: elaboração do autor

Imagem A8: Screeplot PCA, ESEB 2018

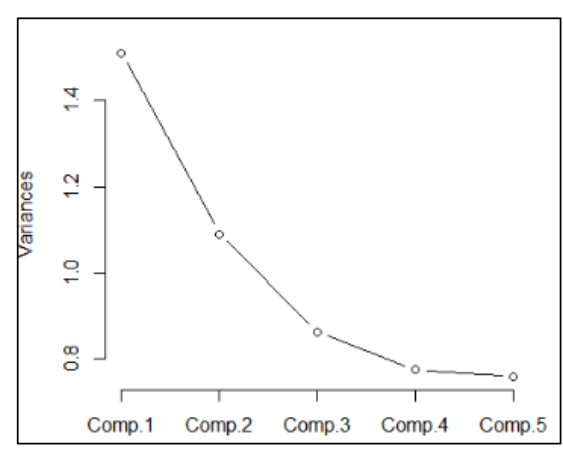

Fonte: elaboração do autor

Caderno Eletrônico de Ciências Sociais, Vitória, v. 9, n. 1, pp. 112-138, 2021 